\title{
PREDICTING THE PRODUCTIVE AND REPRODUCTIVE PERFORMANCE OF EGYPTIAN BALADI CALVES AS A RESPONSE TO GROWTH RATE ASSOCIATED WITH GROWTH HORMONE LEVEL
}

\author{
M.Y. MOHAMED; A.M. ABD EL-HAFEEZ; M.K. EL-BANNA and S.M. ZAHED \\ Animal Production Research Institute, Agricultural Research Center, Ministry of Agriculture, Dokki, Giza, Egypt.
}

Received: 20 August 2019; Accepted: 8 September 2019

\begin{abstract}
This study was conducted to determine whether the growth rate as a response to the growth hormone concentration is a mean of predicting the performance of subsequent growth and reproductive traits in Egyptian Baladi calves. For this purpose, thirty-one calves (16 males and 15 females), were used in this study. The calves of the same sex (male or female) were divided into three groups according to their average daily gain (ADG) from birth to the ninetieth day of age associated with growth hormone (GH) level as follows: low group (L), which recorded less than 500 and $350 \mathrm{~g}$ ADG with less than 18 and $15 \mathrm{ng} / \mathrm{ml} \mathrm{GH}$ concentration for male and female calves, respectively. Moderate group (M), was recorded 500-650 and 350-550 g ADG with 18-20 and 15$17 \mathrm{ng} / \mathrm{ml} \mathrm{GH}$ concentration for male and female calves, respectively. High group $(\mathrm{H})$, which recorded more than 650 and $550 \mathrm{~g}$ ADG with more than 20 and $17 \mathrm{ng} / \mathrm{ml} \mathrm{GH}$ concentration for male and female calves, respectively. Results showed that high group $(\mathrm{H})$ achieved the highest values of ADG associated with the highest levels of serum $\mathrm{GH}$, followed by the moderate group (M), while the low group (L) recorded the lowest values in all ages (from 6 to 18 month of age). Also, the body dimensions (body length, width at hips, height at withers and heart girth) followed the same trend of body weight and ADG. There were significant $(P<0.01)$ differences regarding DM, TDN and CP conversion in some months of age either in male or female calves. The high group that appeared an increase in ADG and GH levels had the highest values of serum protein profile, glucose and cholesterol values followed by the $\mathrm{M}$ group, while the $\mathrm{L}$ group recorded the lowest values. Heifers in the $\mathrm{H}$ group seemed superior in most of the reproductive traits compared to other groups. It could be concluded that using data of GH concentration associated with ADG from birth to the ninetieth day of age may be a useful aid in selecting strategies for improving growth efficiency and reproductive performance.
\end{abstract}

Keywords: Growth hormone; growth rate; reproductive performance; Egyptian calves.

\section{INTRODUCTION}

The Egyptian cattle (Baladi breed) are one of the major sources of red meat supply at the national level. The contribution of cattle population in Egypt is estimated to be 4.61 million heads represented $38.2 \%$ of the total population of dairy breeds, and produce, $39.2 \%$ of the total red meat and $29.4 \%$ of the total milk production (MOA, 2007). Egyptian native cattle are characterized by low milk production inputs used in suckling their borne calves (Habeeb et al., 2017) and also low daily body weight gain (300-500g/d) according to calving season (Habeeb et al., 2014). But they are characterized by high fertility both male or female and also more tolerant of the Egyptian environmental conditions of heat stress as well as diseases. Zahed et al. (2001) reported that the native Baladi cattle could be

Corresponding author: Dr. Mahmoud Yassin Mohamed E-mail address: dr_yassin2005@yahoo.com

Present address: Animal Production Research Institute, Agricultural Research Center, Ministry of Agriculture, Dokki, Giza, Egypt. characterized as a breed of high fertility, adaptable to environmental conditions. High reproductive efficiency is one of the major criteria for achieving a higher economic return and maximizing the gross margin. High reproductive performance is important due to its effect on the longevity of the cows and culling rate.

Growth performance of Baladi calves can be improved by selecting individuals who excel in their growth. There is a strong relationship between the level of growth hormone at the beginning of the calf's life and its growth rate in the future. Oguro et al. (2003) informed that growth hormone secretion or deficiency in cattle could potentially be an indicator of beef or milk productivity. The growth hormone $(\mathrm{GH})$ plays a very important role in many physiological actions (Oberbauer, 2016). Many investigators studied the role of $\mathrm{GH}$ in enhancing growth performance of cattle such as Krasnopiorova et al. (2012) who indicated that GH has wide physiological activities, which include the regulation of growth, lactation and mammary gland development, gluconeogenesis, the activation of 
lipolysis, and the enhancement of amino acid incorporation into muscle protein. Also, Aytac et al. (2015) cleared that GH directly or indirectly plays a notable role in tissue growth and fat metabolism. Thus, it has an important role in reproduction, lactation, and growth stimulation in animals. Besides, the role of $\mathrm{GH}$ in regulating growth and metabolism in cattle is related to the hypothalamic hormone (GHRH). GHRH stimulates the anterior pituitary gland secretion of $\mathrm{GH}$ that increases lipolysis and IGF-1, where IGF-1 mediates many of the growth-promoting effects of $\mathrm{GH}$ and regulates postnatal growth and development. Circulating IGF1 has been studied as an indicator of growth potential in livestock (Connor et al., 1999).

The selection of calves that excel in growth associated with a high level of $\mathrm{GH}$ in pre-weaning helps to save effort and expenditure and achieve the highest possible profit. Connor et al. (1999) reported that $\mathrm{GH}$ response to growth hormone-releasing hormone $(\mathrm{GHRH})$ is associated with subsequent growth may be a useful tool for sire selection and a better predictor of future growth performance in beef production. Therefore, the objective of this study is to determine whether the growth rate associated with growth hormone concentration in Egyptian calves is a mean of predicting the performance of subsequent growth and reproductive traits.

\section{MATERIALS AND METHODS}

The present study was carried out at Sids Experimental station belonging to, Animal Production Research Institute (APRI), Agriculture Research Center, Ministry of Agriculture, located at Beni-Suef Governorate in middle Egypt.

\section{Experimental animals:}

Thirty-one Baladi calves (16 males and 15 females), birth weight of each $21.63 \pm 0.40 \mathrm{~kg}$ on average were used in this study. Both male and female calves were divided into three groups [Low (L), Moderate (M) and High $(\mathrm{H})$ ] according to their average daily gain (ADG) from birth to the ninetieth day of age with associated growth hormone $(\mathrm{GH})$ concentration as shown in Table 1.

Table 1: Average daily gain (ADG) and growth hormone concentration (GH) of male or female calves at 90 day of age.

\begin{tabular}{|c|c|c|}
\hline Groups & ADG, g /day & GH, ng/ml \\
\hline \multicolumn{3}{|c|}{ Male } \\
\hline Low (L) & $\overline{<500}$ & $<18$ \\
\hline Moderate (M) & $500-650$ & $18-20$ \\
\hline $\operatorname{High}(\mathrm{H})$ & $>650$ & $>20$ \\
\hline \multicolumn{3}{|c|}{ Female } \\
\hline Low $(\mathrm{L})$ & $<350$ & $<15$ \\
\hline Moderate (M) & $350-550$ & $15-17$ \\
\hline $\operatorname{High}(\mathrm{H})$ & $>550$ & $>17$ \\
\hline
\end{tabular}

\section{Management and feeding:}

During the first three days of calves' life, they were fed individually on colostrum at a rate of $10 \%$ of body weight given in two meals. The calves were fed individually on milk at a rate of $10 \%$ of body weight given in two meals for six weeks. The milk allowances were reduced gradually until weaning at 15 weeks of age. Calf starter and hay were available for calves from the beginning of the third week of age.

After weaning the calves were fed to cover their requirements of dry matter $(\mathrm{DM})$, protein and total digestible nutrients (TDN) for growing according to NRC (2001) and were adjusted monthly according to body weight change till the end of the experiment. The calves were fed on a total mixed ration (TMR) consisted of a $40 \%$ concentrate mixture, $30 \%$ berseem hay and $30 \%$ rice straw. Total mixed ration was offered twice daily (at 8 am and $3 \mathrm{pm}$ ). Fresh and clean drinking water was available at all times.
Animals were fed individually their respective diets in six adjacent separate open shaded yards. Dry matter intake was individually recorded for each animal. Fasted for 16 hours, calves were individually weighed in the morning prior to drinking and feeding. Body weights were measured monthly for 18 months.

\section{Body dimensions:}

At 3, 6, 9, 12, 15 and 18 month old, the following measurements were obtained from each animal: Body Length: The average of left and right side measurements (using a tape) of the distance between the point of the shoulder; Width at Hips: Distance between the lateral surfaces of the tuber coxae, measured with calipers; Height at Withers: Measured on the dorsal midline at the highest point on the withers using metal tape; Heart Girth: Body circumference immediately posterior to the front leg, measured with a tape. 


\section{Reproductive traits of heifers:}

Fifteen heifers in the previous groups (L, M, and $\mathrm{H}$ ) were observed for estrus to determine the age at first estrus. First estrus detection for heifers was carried out three times daily at 8 am, 4 and 9 p.m. using a teaser bull. The teaser was left with the heifers for a period of 30 minutes at each check time to recognize the heifers on heat. All heifers were palpated 5 to 11 days following the pubertal estrus to confirm ovulation. Heifers were served at the second estrus. Body weight of heifers was recorded at the first estrus, first service, conception, and immediately post-parturition. The bulls were used to breed the heifers after 12-14 hours from onset estrus. The bulls were highly fertile as indicated by their previous production performance in the same farm. Pregnancy was ascertained by rectal palpation 45 days after the date of mating. Dystocia cases of heifers were recorded at parturition. Also, the body weight of newborn calves and stillbirth cases for 48 hours after parturition were recorded.

\section{Blood samples and serum analysis:}

Blood samples of the experimental Baladi calves were collected individually starting from the $90^{\text {th }}$ day and thirty days intervals throughout the experimental period. Blood samples were collected from the jugular vein into serum separator tubes (Venoject). After clotting at room temperature, sera were separated by centrifugation at $1,800 \square g$ for $20 \mathrm{~min}$ and transferred to plastic tubes. Sera were stored at $20{ }^{\circ} \mathrm{C}$ for subsequent $\mathrm{GH}$ concentration analysis by using a commercial ELISA kit (Beijing Sino-UK Institute of Biological Technology, Beijing, China) according to Yang et al. (2019). Serum glucose concentration was measured by the glucose/oxidase method using a commercial kit (Biolabo, Glucose
GOD-PAP, Cat. No 87109). Serum total cholesterol levels were measured using a Technician DAX 72 auto-analyzer and accompanying kits. Serum total protein and albumin content were estimated using the colorimetric method, kits that were obtained from Biodiognostic. CAT. No. TP 2020 and AB 1010. Globulin content was evaluated by subtracting albumin from total protein.

\section{Statistical Analysis:}

Data were expressed as means $( \pm$ S.E.) and statistical analyses were performed with SPSS Version 22.0 for Windows (SPSS, 2013). Duncan's New Multiple Range Test (Duncan, 1955) of the same SPSS program was applied to determine significant differences among all tested treatments. Probability values $\leq 5 \%$ were considered significant.

\section{RESULTS}

\section{Growth hormone and growth performance:}

The data shown in Table 2 are considered the basis for this study. Male and female calves were divided into three groups [Low (L), Moderate (M) and High (H)] according to the average daily gain (ADG) from birth to the ninetieth day of age associated with the concentration of growth hormone $(\mathrm{GH})$. H group had the highest values of ADG associated with the highest concentrations of serum $\mathrm{GH}$, followed by the $\mathrm{M}$ group, while the $\mathrm{L}$ group recorded the lowest values. Differences between groups were highly significant $(P<0.01)$. The superiority of the $\mathrm{H}$ group either in male or female calves in daily gain associated with the highest level of $\mathrm{GH}$ compared with the other groups.

Table 2: Weight of calves at birth, the ninetieth day of age, average daily gain (ADG) and growth hormone concentration $(\mathrm{GH})$ of male and female calves.

\begin{tabular}{cccccc}
\hline Terms & No. & Birth Wt. & Wt. at 90-day & ADG, g/day & GH, ng/ml \\
\hline & \multicolumn{7}{c}{ Male } & & \\
\hline L & 5 & $21.47 \pm 0.43$ & $65.02 \pm 0.76^{\mathrm{c}}$ & $0.483 \pm 0.01^{\mathrm{c}}$ & $16.30 \pm 0.35^{\mathrm{c}}$ \\
\hline M & 5 & $21.63 \pm 0.39$ & $74.38 \pm 1.08^{\mathrm{b}}$ & $0.587 \pm 0.01^{\mathrm{b}}$ & $19.31 \pm 0.16^{\mathrm{b}}$ \\
\hline H & 6 & $21.75 \pm 0.58$ & $83.55 \pm 0.41^{\mathrm{a}}$ & $0.687 \pm 0.01^{\mathrm{a}}$ & $20.88 \pm 0.16^{\mathrm{a}}$ \\
\hline Sig. & \multicolumn{7}{c}{ Ns } & Female & $* *$ & $* *$ \\
\hline L & 5 & $21.38 \pm 0.37$ & $49.96 \pm 0.46^{\mathrm{c}}$ & $0.318 \pm 0.01^{\mathrm{c}}$ & $14.48 \pm 0.12^{\mathrm{c}}$ \\
\hline M & 5 & $21.70 \pm 0.31$ & $62.54 \pm 1.47^{\mathrm{b}}$ & $0.453 \pm 0.02^{\mathrm{b}}$ & $16.31 \pm 0.05^{\mathrm{b}}$ \\
\hline H & 5 & $21.82 \pm 0.33$ & $75.56 \pm 0.55^{\mathrm{a}}$ & $0.597 \pm 0.01^{\mathrm{a}}$ & $18.42 \pm 0.42^{\mathrm{a}}$ \\
\hline Sig. & 5 & Ns & $* *$ & $* *$ & $* *$ \\
\hline
\end{tabular}

a, b and c: Means of each column with different superscripts are significantly different $(P<0.05)$. Wt: weight; L: Low group, M: Moderate group, H: High group. Sig = Significant, Ns = Not significant $(P>0.05), * *=(P<0.01)$.

${ }^{1} \mathrm{GH}(\mathrm{ng} / \mathrm{ml})$ was determined at 90-day of age 
Serum GH concentrations from 6 to 18 months old of male and female calves are shown in Table 3. The overall mean of $\mathrm{GH}$ reached the highest values in the high group of both male and female calves. However, the hormone level was high at six months of age and diminished with advanced age until it reached its lowest value at the age of 18 months. It started at $9.74,11.76$ and 12.82 at 6 months until it reached $4.50,5.03$, and 5.94 at the age of 18 months in males, while its concentrations in females were $9.52,10.97,12.30$ at 6 months and 3.34, 4.51, and 5.71 at 18 months.
Body weight change and ADG are shown in Figure 1 and Table 4. It was expected that body weight and daily gain of calves would take the opposite trend that found with growth hormone as calves began with small weights and growth rates at the beginning of life and increased with age. The highest average daily growth rates were very pronounced $(P<0.01)$ in the $\mathrm{H}$ group $(0.667 \& 0.623 \mathrm{~g} /$ day) compared to the other two groups $(0.547 \& 0.520$ in $\mathrm{M}$ group; $0.408 \& 0.357$ in $\mathrm{L}$ group) in male and female, respectively.

Table 3: Growth hormone level (GH, ng/ml) of male and female calves from 6 to 18 months old.

\begin{tabular}{|c|c|c|c|c|c|c|}
\hline \multirow{2}{*}{ Terms } & \multicolumn{5}{|c|}{ Age (month) } & \multirow{2}{*}{ Means } \\
\hline & 6 & 9 & 12 & 15 & 18 & \\
\hline \multicolumn{7}{|c|}{ Male } \\
\hline $\mathrm{L}$ & $9.74 \pm 0.19^{c}$ & $8.53 \pm 0.26^{\mathrm{c}}$ & $6.91 \pm 0.41^{\mathrm{c}}$ & $5.71 \pm 0.42^{b}$ & $4.50 \pm 0.44^{b}$ & $8.62 \pm 0.27^{\mathrm{c}}$ \\
\hline $\mathrm{M}$ & $11.76 \pm 0.45^{b}$ & $9.88 \pm 0.26^{\mathrm{b}}$ & $7.35 \pm 0.16^{b}$ & $6.19 \pm 0.21^{b}$ & $5.03 \pm 0.30^{\mathrm{ab}}$ & $9.92 \pm 0.22^{b}$ \\
\hline $\mathrm{H}$ & $12.82 \pm 0.16^{\mathrm{a}}$ & $11.06 \pm 0.08^{\mathrm{a}}$ & $8.63 \pm 0.24^{\mathrm{a}}$ & $7.29 \pm 0.20^{\mathrm{a}}$ & $5.94 \pm 0.22^{\mathrm{a}}$ & $11.10 \pm 0.11^{\mathrm{a}}$ \\
\hline Sig. & $* *$ & $* *$ & $* *$ & $* *$ & $*$ & $* *$ \\
\hline \multicolumn{7}{|c|}{ Female } \\
\hline $\mathrm{L}$ & $9.52 \pm 0.39^{c}$ & $7.25 \pm 0.38^{\mathrm{c}}$ & $5.37 \pm 0.16^{\mathrm{c}}$ & $4.06 \pm 0.14^{\mathrm{c}}$ & $3.34 \pm 0.31^{\mathrm{c}}$ & $7.34 \pm 0.21^{\mathrm{c}}$ \\
\hline $\mathrm{M}$ & $10.97 \pm 0.44^{b}$ & $8.75 \pm 0.21^{b}$ & $6.92 \pm 0.18^{b}$ & $5.82 \pm 0.23^{b}$ & $4.51 \pm 0.16^{b}$ & $8.88 \pm 0.17^{b}$ \\
\hline $\mathrm{H}$ & $12.30 \pm 0.21^{\mathrm{a}}$ & $10.39 \pm 0.25^{\mathrm{a}}$ & $8.22 \pm 0.17^{\mathrm{a}}$ & $7.22 \pm 0.15^{\mathrm{a}}$ & $5.71 \pm 0.20^{\mathrm{a}}$ & $10.38 \pm 0.16^{\mathrm{a}}$ \\
\hline Sig. & $* *$ & $* *$ & $* *$ & $* *$ & $* *$ & $* *$ \\
\hline
\end{tabular}

$\mathrm{a}, \mathrm{b}$ and $\mathrm{c}$ : Means of each column with different superscripts are significantly different $(P<0.05)$. L: Low group, M: Moderate group, H: High group. $\mathrm{Sig}=$ Significant, $*=(P<0.05), * *=(P<0.01)$.

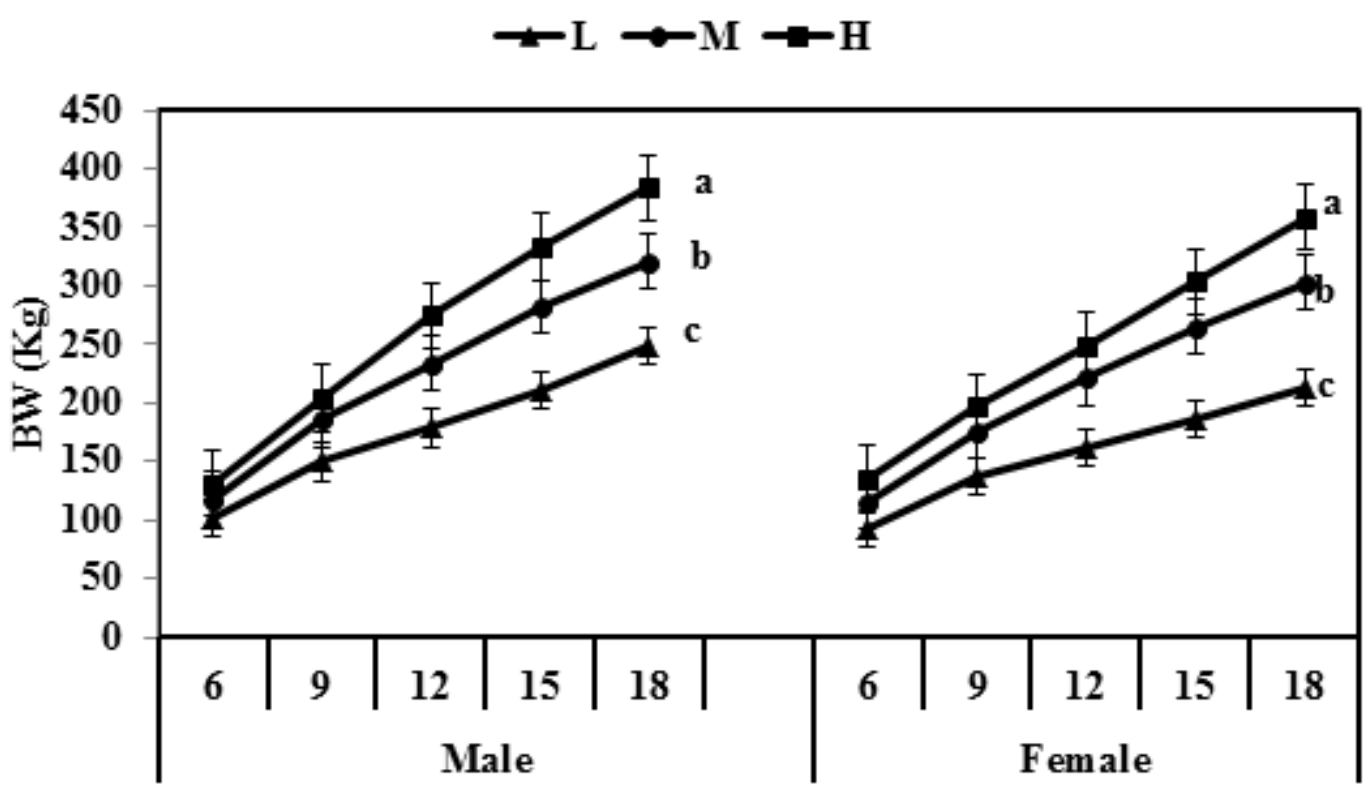

Age (month)

Figure 1: Body weight of male and female calves from 6- 18 months old

$\mathrm{a}, \mathrm{b}$ and $\mathrm{c}$ : Means of different superscripts are significantly different $(P<0.05)$.

L: Low group, M: Moderate group, H: High group. 
Table 4: Average daily gain (ADG, Kg) of male and female calves from 3- 18 months old.

\begin{tabular}{|c|c|c|c|c|c|c|}
\hline \multirow{2}{*}{ Terms } & \multicolumn{5}{|c|}{ Age (month) } & \multirow{2}{*}{ Means } \\
\hline & $3-6$ & $6-9$ & $9-12$ & $12-15$ & $15-18$ & \\
\hline \multicolumn{7}{|c|}{ Male } \\
\hline $\mathrm{L}$ & $0.397 \pm 0.02^{\mathrm{c}}$ & $0.542 \pm 0.04^{\mathrm{b}}$ & $0.320 \pm 0.01^{\mathrm{b}}$ & $0.352 \pm 0.02^{\mathrm{c}}$ & $0.422 \pm 0.06^{\mathrm{b}}$ & $0.408 \pm 0.02^{\mathrm{c}}$ \\
\hline $\mathrm{M}$ & $0.483 \pm 0.01^{\mathrm{b}}$ & $0.753 \pm 0.06^{\mathrm{a}}$ & $0.537 \pm 0.02^{b}$ & $0.535 \pm 0.02^{b}$ & $0.430 \pm 0.02^{b}$ & $0.547 \pm 0.02^{b}$ \\
\hline $\mathrm{H}$ & $0.531 \pm 0.01^{\mathrm{a}}$ & $0.806 \pm 0.03^{\mathrm{a}}$ & $0.783 \pm 0.12^{\mathrm{a}}$ & $0.649 \pm 0.02^{a}$ & $0.569 \pm 0.03^{\mathrm{a}}$ & $0.667 \pm 0.03^{\mathrm{a}}$ \\
\hline Sig. & $* *$ & $* *$ & $* *$ & $* *$ & $*$ & $* *$ \\
\hline \multicolumn{7}{|c|}{ Female } \\
\hline $\mathrm{L}$ & $0.470 \pm 0.01^{\mathrm{c}}$ & $0.490 \pm 0.04^{\mathrm{b}}$ & $0.280 \pm 0.01^{b}$ & $0.267 \pm 0.03^{\mathrm{c}}$ & $0.315 \pm 0.02^{\mathrm{c}}$ & $0.357 \pm 0.01^{\mathrm{c}}$ \\
\hline $\mathrm{M}$ & $0.587 \pm 0.01^{\mathrm{b}}$ & $0.673 \pm 0.04^{\mathrm{a}}$ & $0.502 \pm 0.06^{\mathrm{a}}$ & $0.488 \pm 0.05^{b}$ & $0.418 \pm 0.02^{b}$ & $0.520 \pm 0.03^{b}$ \\
\hline $\mathrm{H}$ & $0.660 \pm 0.04^{\mathrm{a}}$ & $0.683 \pm 0.08^{\mathrm{a}}$ & $0.578 \pm 0.03^{\mathrm{a}}$ & $0.613 \pm 0.04^{\mathrm{a}}$ & $0.603 \pm 0.02^{\mathrm{a}}$ & $0.623 \pm 0.03^{\mathrm{a}}$ \\
\hline Sig. & $* *$ & $*$ & $* *$ & $* *$ & $* *$ & $* *$ \\
\hline
\end{tabular}

a, b and c: Means of each column with different superscripts are significantly different $(P<0.05)$. L: Low group, M: Moderate group, H: High group. $\mathrm{Sig}=$ Significant, $*=(P<0.05), * *=(P<0.01)$.

\section{Body dimensions}

Body dimensions $(\mathrm{cm})$ which included body length (BL), width at hips (WH), height at withers (HW) and heart girth (HG) of three experimental groups (L, M, and $\mathrm{H}$ ) for male and female Egyptian calves are shown in Figure 2. The obtained results showed that the body dimensions (BL, WH, HW, and HG) followed the same trend as body weight and ADG (Figure $1 \&$ Table 4). The $\mathrm{H}$ group had the highest values (146.0 \& $143.4 \mathrm{~cm} \mathrm{BL;} 39.1 \& 34.8 \mathrm{~cm} \mathrm{WH}$; $151.0 \& 149.8 \mathrm{~cm} \mathrm{HW} ; 156.5 \& 152.2 \mathrm{~cm} \mathrm{HG})$ of body measurements compared to the $\mathrm{M}$ group (135.8 \& $132.4 \mathrm{~cm} \mathrm{BL} ; 37.0$ \& $32.6 \mathrm{~cm} \mathrm{WH} ; 142.0$ \& $139.6 \mathrm{~cm} \mathrm{HW} ; 145.4 \& 141.2 \mathrm{~cm} \mathrm{HG})$ and L group (118.2 \& $116.8 \mathrm{~cm} \mathrm{BL} ; 32.8 \& 29.8 \mathrm{~cm} \mathrm{WH} ; 127.8$ $\& 123.6 \mathrm{~cm} \mathrm{HW} ; 125.2 \& 124.0 \mathrm{~cm} \mathrm{HG})$ in male and female, respectively.
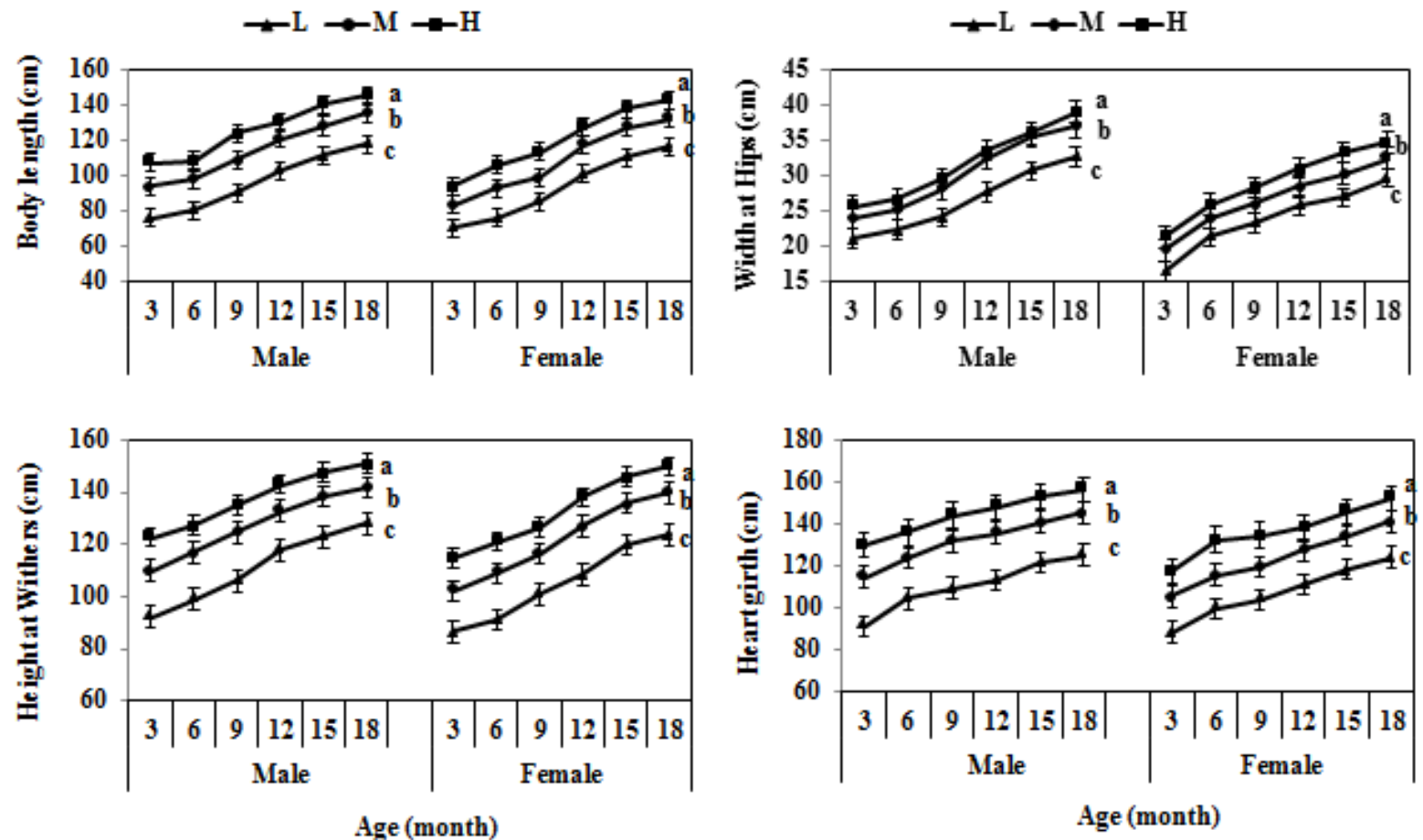

Figure 2: Body dimensions $(\mathrm{cm})$ of male and female calves from 3-18 months old $\mathrm{a}, \mathrm{b}$ and $\mathrm{c}$ : Means of different superscripts are significantly different $(P<0.05)$.

L: Low group, M: Moderate group, H: High group. 


\section{Feed intake and feed conversion:}

Tables 5 and 6 show that total DM and daily feed unit intake as TDN and CP for male and female calves aged 3-18 months. There is a gradual increase within the same group and sex in DM, TDN and CP intake with advancing age and body weight.

High group was the highest $(P<0.01)$ one in feed unite intake as DM, TDN or CP (percentage change $=49.91 \& 24.58 ; 40.07 \& 49.19 ; 26.70 \& 48.10$, respectively) in male and female calves followed by $\mathrm{M}$ group (percentage change $=28.28 \& 10.72 ; 24.34$
\& 33.33; $11.61 \& 32.66$, respectively), while $\mathrm{L}$ group that was the lowest one. However, Tables $7 \&$ 8 showed that feed conversion values of DM, TDN and $\mathrm{CP} / \mathrm{kg}$ gain was reduced (i.e. improved) by increasing of $\mathrm{GH}$ and $\mathrm{ADG}$ levels in $\mathrm{H}$ group (percentage change $=-8.25 \&-20.76 ;-14.75 \&-$ $20.92 ;-21.59 \&-20.78$, respectively) in male and female calves followed by $\mathrm{M}$ group (percentage change $=-4.93 \&-10.59 ;-8.30 \&-10.79 ;-17.05 \&-$ 10.39 , respectively) compared to the $\mathrm{L}$ group that had poor feed conversion.

Table 5: Dry matter intake (DMI), daily feed unit intake as total digestible nutrients (TDN) and crude protein (CP) of male calves from 3- 18 months old.

\begin{tabular}{|c|c|c|c|c|c|c|}
\hline \multirow{2}{*}{ Terms } & \multicolumn{5}{|c|}{ Age (month) } & \multirow{2}{*}{ Means } \\
\hline & $3-6$ & $6-9$ & $9-12$ & $12-15$ & $15-18$ & \\
\hline \multicolumn{7}{|c|}{ DMI (Kg/h/d) } \\
\hline $\mathrm{L}$ & $3.50 \pm 0.11^{\mathrm{c}}$ & $4.48 \pm 0.14^{\mathrm{c}}$ & $5.35 \pm 0.15^{\mathrm{c}}$ & $6.29 \pm 0.16^{c}$ & $7.43 \pm 0.26^{\mathrm{c}}$ & $5.41 \pm 0.15^{\mathrm{c}}$ \\
\hline $\bar{M}$ & $4.02 \pm 0.08^{b}$ & $5.57 \pm 0.11^{b}$ & $7.01 \pm 0.15^{b}$ & $8.46 \pm 0.20^{b}$ & $9.62 \pm 0.20^{6}$ & $6.94 \pm 0.14^{b}$ \\
\hline $\mathrm{H}$ & $4.43 \pm 0.10^{\mathrm{a}}$ & $6.39 \pm 0.21^{\mathrm{a}}$ & $8.24 \pm 0.30^{\mathrm{a}}$ & $9.99 \pm 0.34^{\mathrm{a}}$ & $11.52 \pm 0.35^{\mathrm{a}}$ & $8.11 \pm 0.25^{\mathrm{a}}$ \\
\hline Sig. & $* *$ & $* *$ & $* *$ & $* *$ & $* *$ & $* *$ \\
\hline \multicolumn{7}{|c|}{ TDN $(\mathrm{Kg} / \mathrm{h} / \mathrm{d})$} \\
\hline $\mathrm{L}$ & $2.18 \pm 0.07^{\mathrm{c}}$ & $2.62 \pm 0.10^{c}$ & $3.13 \pm 0.04^{b}$ & $3.48 \pm 0.08^{\mathrm{c}}$ & $3.95 \pm 0.12^{\mathrm{c}}$ & $3.07 \pm 0.07^{\mathrm{c}}$ \\
\hline $\mathrm{M}$ & $2.51 \pm 0.05^{b}$ & $3.19 \pm 0.06^{b}$ & $4.02 \pm 0.09^{\mathrm{a}}$ & $4.40 \pm 0.10^{b}$ & $4.97 \pm 0.09^{b}$ & $3.82 \pm 0.07^{b}$ \\
\hline $\mathrm{H}$ & $2.77 \pm 0.06^{\mathrm{a}}$ & $3.66 \pm 0.12^{\mathrm{a}}$ & $4.28 \pm 0.16^{\mathrm{a}}$ & $5.06 \pm 0.17^{\mathrm{a}}$ & $5.73 \pm 0.17^{\mathrm{a}}$ & $4.30 \pm 0.13^{\mathrm{a}}$ \\
\hline Sig. & $* *$ & $* *$ & $* *$ & $* *$ & $* *$ & $* *$ \\
\hline \multicolumn{7}{|c|}{$\mathrm{CP}(\mathrm{g} / \mathrm{h} / \mathrm{d})$} \\
\hline $\mathrm{L}$ & $533.40 \pm 14.08^{\mathrm{c}}$ & $632.60 \pm 13.56^{\mathrm{a}}$ & $694.20 \pm 5.47^{\mathrm{a}}$ & $728.60 \pm 8.48^{\mathrm{c}}$ & $769.20 \pm 17.30^{c}$ & $636.56 \pm 8.95^{\mathrm{c}}$ \\
\hline $\mathrm{M}$ & $585.60 \pm 9.69^{b}$ & $683.00 \pm 13.57^{\mathrm{a}}$ & $737.80 \pm 4.48^{\mathrm{a}}$ & $824.40 \pm 19.58^{b}$ & $936.20 \pm 19.24^{b}$ & $710.47 \pm 10.33^{b}$ \\
\hline $\mathrm{H}$ & $644.81 \pm 14.90^{\mathrm{a}}$ & $783.84 \pm 25.48^{b}$ & $802.46 \pm 29.45^{b}$ & $972.98 \pm 32.89^{\mathrm{a}}$ & $1122.07 \pm 33.86^{\mathrm{a}}$ & $806.54 \pm 23.62^{\mathrm{a}}$ \\
\hline Sig. & $* *$ & $* *$ & $* *$ & $* *$ & $* *$ & $* *$ \\
\hline
\end{tabular}

Table 6: Dry matter intake (DMI), daily feed unit intake as total digestible nutrients (TDN) and crude protein (CP) of female calves from 3- 18 months old.

\begin{tabular}{|c|c|c|c|c|c|c|}
\hline \multirow{2}{*}{ Terms } & \multicolumn{5}{|c|}{ Age (month) } & \multirow{2}{*}{ Means } \\
\hline & $3-6$ & $6-9$ & $9-12$ & $12-15$ & $15-18$ & \\
\hline \multicolumn{7}{|c|}{ DMI (Kg/h/d) } \\
\hline $\mathrm{L}$ & $3.28 \pm 0.11^{\mathrm{c}}$ & $4.09 \pm 0.09^{c}$ & $4.85 \pm 0.06^{\mathrm{c}}$ & $5.57 \pm 0.11^{\mathrm{c}}$ & $6.41 \pm 0.11^{\mathrm{c}}$ & $4.46 \pm 0.08^{\mathrm{c}}$ \\
\hline $\mathrm{M}$ & $3.97 \pm 0.06^{b}$ & $5.34 \pm 0.15^{b}$ & $6.63 \pm 0.27^{b}$ & $7.94 \pm 0.39^{b}$ & $9.07 \pm 0.40^{b}$ & $5.99 \pm 0.21^{b}$ \\
\hline $\mathrm{H}$ & $4.18 \pm 0.24^{\mathrm{a}}$ & $5.90 \pm 0.30^{\mathrm{a}}$ & $7.46 \pm 0.36^{\mathrm{a}}$ & $9.11 \pm 0.37^{\mathrm{a}}$ & $10.75 \pm 0.39^{\mathrm{a}}$ & $6.74 \pm 0.29^{\mathrm{a}}$ \\
\hline Sig. & $* *$ & $* *$ & $* *$ & $* *$ & $* *$ & $* *$ \\
\hline \multicolumn{7}{|c|}{ TDN (Kg/h/d) } \\
\hline $\mathrm{L}$ & $2.05 \pm 0.07^{\mathrm{c}}$ & $2.35 \pm 0.05^{\mathrm{c}}$ & $2.52 \pm 0.03^{\mathrm{c}}$ & $2.82 \pm 0.05^{\mathrm{c}}$ & $3.19 \pm 0.06^{\mathrm{c}}$ & $2.46 \pm 0.05 c$ \\
\hline $\mathrm{M}$ & $2.48 \pm 0.03^{b}$ & $3.06 \pm 0.09^{b}$ & $3.45 \pm 0.14^{b}$ & $4.02 \pm 0.20^{b}$ & $4.52 \pm 0.20^{\mathrm{b}}$ & $3.28 \pm 0.11^{b}$ \\
\hline $\mathrm{H}$ & $2.61 \pm 0.15^{\mathrm{a}}$ & $3.38 \pm 0.18^{\mathrm{a}}$ & $3.88 \pm 0.19^{\mathrm{a}}$ & $4.62 \pm 0.19^{\mathrm{a}}$ & $5.35 \pm 0.20^{\mathrm{a}}$ & $3.67 \pm 0.16^{\mathrm{a}}$ \\
\hline Sig. & $* *$ & $* *$ & $* *$ & $* *$ & $* *$ & $* *$ \\
\hline \multicolumn{7}{|c|}{$\mathrm{CP}(\mathrm{g} / \mathrm{h} / \mathrm{d})$} \\
\hline $\mathrm{L}$ & $476.84 \pm 15.31^{\mathrm{c}}$ & $501.95 \pm 11.35^{\mathrm{c}}$ & $472.41 \pm 5.68^{\mathrm{c}}$ & $542.57 \pm 10.26^{\mathrm{c}}$ & $625.01 \pm 11.08^{\mathrm{c}}$ & $505.86 \pm 9.92^{c}$ \\
\hline $\mathrm{M}$ & $578.15 \pm 8.25^{b}$ & $655.04 \pm 18.35^{b}$ & $646.06 \pm 26.04^{b}$ & $774.10 \pm 37.78^{b}$ & $884.02 \pm 38.73^{b}$ & $671.07 \pm 21.61^{b}$ \\
\hline $\mathrm{H}$ & $607.84 \pm 34.96^{\mathrm{a}}$ & $723.49 \pm 37.34^{\mathrm{a}}$ & $726.74 \pm 34.91^{\mathrm{a}}$ & $888.11 \pm 35.73^{\mathrm{a}}$ & $1047.14 \pm 38.45^{\mathrm{a}}$ & $748.70 \pm 31.91^{\mathrm{a}}$ \\
\hline Sig. & $* *$ & $* *$ & *** & $* *$ & $* *$ & $* *$ \\
\hline
\end{tabular}

$\mathrm{a}, \mathrm{b}$ and $\mathrm{c}$ : Means of each column with different superscripts are significantly different $(P<0.05)$. L: Low group, M: Moderate group, $\mathrm{H}$ : High group. $\mathrm{Sig}=$ Significant, $* *=(P<0.01)$. 
Table 7: Feed conversion (FC) / Kg daily gain of dry matter intake (DM, Kg) and as total digestible nutrients (TDN, $\mathrm{Kg}$ ) and crude protein $(\mathrm{CP}, \mathrm{Kg})$ of male calves from 3-18 months old.

\begin{tabular}{|c|c|c|c|c|c|c|}
\hline \multirow{2}{*}{ Terms } & \multicolumn{5}{|c|}{ Age (month) } & \multirow{2}{*}{ Means } \\
\hline & $3-6$ & $6-9$ & $9-12$ & $12-15$ & $15-18$ & \\
\hline \multicolumn{7}{|c|}{ FC-DMI / Kg } \\
\hline $\mathrm{L}$ & $8.91 \pm 0.30$ & $8.45 \pm 0.43$ & $16.62 \pm 0.42$ & $18.23 \pm 0.83^{\mathrm{a}}$ & $18.81 \pm 1.62$ & $14.20 \pm 0.34^{\mathrm{a}}$ \\
\hline $\bar{M}$ & $8.37 \pm 0.28$ & $7.57 \pm 0.39$ & $13.16 \pm 0.32$ & $15.84 \pm 0.24^{\mathrm{a}}$ & $22.57 \pm 0.85$ & $13.50 \pm 0.20^{\mathrm{ab}}$ \\
\hline $\mathrm{H}$ & $8.34 \pm 0.28$ & $7.99 \pm 0.36$ & $12.55 \pm 2.10$ & $15.39 \pm 0.29^{b}$ & $20.68 \pm 1.10$ & $12.99 \pm 0.22^{b}$ \\
\hline Sig. & $\mathrm{Ns}$ & Ns & $\mathrm{Ns}$ & $* *$ & Ns & $*$ \\
\hline \multicolumn{7}{|c|}{ FC-TDN / Kg } \\
\hline $\mathrm{L}$ & $5.56 \pm 0.19$ & $4.93 \pm 0.24$ & $9.73 \pm 0.17^{\mathrm{a}}$ & $10.12 \pm 0.54^{\mathrm{a}}$ & $9.99 \pm 0.84$ & $8.07 \pm 0.15^{\mathrm{a}}$ \\
\hline $\bar{M}$ & $5.23 \pm 0.18$ & $4.34 \pm 0.22$ & $7.55 \pm 0.18^{b}$ & $8.24 \pm 0.12^{b}$ & $11.68 \pm 0.42$ & $7.40 \pm 0.11^{b}$ \\
\hline $\mathrm{H}$ & $5.21 \pm 0.17$ & $4.58 \pm 0.21$ & $6.52 \pm 1.09^{b}$ & $7.80 \pm 0.15^{\mathrm{b}}$ & $10.29 \pm 0.55$ & $6.88 \pm 0.10^{c}$ \\
\hline Sig. & Ns & Ns & $*$ & $* *$ & Ns & $* *$ \\
\hline \multicolumn{7}{|c|}{ FC-CP / g } \\
\hline $\mathrm{L}$ & $1.36 \pm 0.05^{\mathrm{a}}$ & $1.21 \pm 0.09^{\mathrm{a}}$ & $2.16 \pm 0.04^{\mathrm{a}}$ & $2.12 \pm 0.12^{\mathrm{a}}$ & $1.96 \pm 0.19$ & $1.76 \pm 0.05^{\mathrm{a}}$ \\
\hline $\mathrm{M}$ & $1.22 \pm 0.03^{b}$ & $0.93 \pm 0.05^{\mathrm{b}}$ & $1.39 \pm 0.05^{\mathrm{b}}$ & $1.54 \pm 0.02^{b}$ & $2.20 \pm 0.08$ & $1.46 \pm 0.02^{b}$ \\
\hline $\mathrm{H}$ & $1.21 \pm 0.04^{b}$ & $0.98 \pm 0.04^{b}$ & $1.22 \pm 0.21^{b}$ & $1.50 \pm 0.03^{\mathrm{b}}$ & $2.02 \pm 0.11$ & $1.38 \pm 0.02^{b}$ \\
\hline Sig. & $*$ & $*$ & $* *$ & $* *$ & $\mathrm{Ns}$ & $* *$ \\
\hline
\end{tabular}

$\mathrm{a}, \mathrm{b}$ and $\mathrm{c}$ : Means of each column with different superscripts are significantly different $(P<0.05)$. L: Low group, M: Moderate group, H: High group. $\mathrm{Sig}=$ Significant, $\mathrm{Ns}=$ Not significant $(P>0.05),{ }^{*}=(P<0.05),{ }^{* *}=(P<0.01)$.

Table 8: Feed conversion (FC) / Kg daily gain of dry matter intake (DM, $\mathrm{Kg}$ ) and as total digestible nutrients (TDN, $\mathrm{Kg}$ ) and crude protein $(\mathrm{CP}, \mathrm{Kg}$ ) of female calves from 3- 18 months old.

\begin{tabular}{|c|c|c|c|c|c|c|}
\hline \multirow{2}{*}{ Terms } & \multicolumn{5}{|c|}{ Age (month) } & \multirow{2}{*}{ Means } \\
\hline & $3-6$ & $6-9$ & $9-12$ & $12-15$ & $15-18$ & \\
\hline \multicolumn{7}{|c|}{ FC-DM / Kg } \\
\hline $\mathrm{L}$ & $7.01 \pm 0.33$ & $8.65 \pm 0.64$ & $17.63 \pm 1.04^{\mathrm{a}}$ & $21.74 \pm 1.47^{\mathrm{a}}$ & $20.77 \pm 0.99^{\mathrm{a}}$ & $13.97 \pm 0.24^{\mathrm{a}}$ \\
\hline $\mathrm{M}$ & $6.79 \pm 0.09$ & $8.08 \pm 0.41$ & $14.15 \pm 1.38^{b}$ & $17.27 \pm 1.59^{b}$ & $21.99 \pm 1.30^{\mathrm{a}}$ & $12.49 \pm 0.49^{b}$ \\
\hline $\mathrm{H}$ & $7.25 \pm 0.93$ & $9.25 \pm 0.52$ & $12.43 \pm 0.81^{b}$ & $14.00 \pm 1.33^{\mathrm{b}}$ & $16.16 \pm 1.79^{b}$ & $11.07 \pm 0.21^{\mathrm{c}}$ \\
\hline \multicolumn{7}{|c|}{ FC-TDN / Kg } \\
\hline $\mathrm{L}$ & $4.38 \pm 0.20$ & $4.96 \pm 0.37$ & $9.17 \pm 0.54^{\mathrm{a}}$ & $11.01 \pm 0.75^{\mathrm{a}}$ & $10.33 \pm 0.49^{\mathrm{ab}}$ & $7.60 \pm 0.12^{\mathrm{a}}$ \\
\hline $\mathrm{M}$ & $4.24 \pm 0.06$ & $4.63 \pm 0.24$ & $7.36 \pm 0.72^{b}$ & $8.75 \pm 0.81^{b}$ & $10.94 \pm 0.65^{\mathrm{a}}$ & $6.78 \pm 0.25^{b}$ \\
\hline $\mathrm{H}$ & $4.96 \pm 1.02$ & $5.63 \pm 0.56$ & $6.86 \pm 0.27^{b}$ & $7.41 \pm 0.44^{b}$ & $9.2 \pm 0.41^{b}$ & $6.01 \pm 0.13^{\mathrm{c}}$ \\
\hline Sig. & Ns & $\mathrm{Ns}$ & $*$ & $* *$ & $*$ & $* *$ \\
\hline \multicolumn{7}{|c|}{ FC-CP / g } \\
\hline $\mathrm{L}$ & $1.02 \pm 0.05$ & $1.06 \pm 0.08$ & $1.72 \pm 0.10$ & $2.12 \pm 0.14$ & $2.02 \pm 0.10^{\mathrm{ab}}$ & $1.54 \pm 0.02^{\mathrm{a}}$ \\
\hline $\mathrm{M}$ & $0.99 \pm 0.01$ & $0.99 \pm 0.05$ & $1.38 \pm 0.13$ & $1.69 \pm 0.16$ & $2.14 \pm 0.13^{\mathrm{a}}$ & $1.38 \pm 0.05^{\mathrm{b}}$ \\
\hline $\mathrm{H}$ & $2.02 \pm 1.10$ & $1.98 \pm 0.89$ & $1.94 \pm 0.67$ & $2.85 \pm 1.38$ & $1.74 \pm 0.06^{\mathrm{b}}$ & $1.22 \pm 0.03^{\mathrm{c}}$ \\
\hline Sig. & Ns & Ns & Ns & Ns & $*$ & $* *$ \\
\hline
\end{tabular}

a, b and c: Means of each column with different superscripts are significantly different $(P<0.05)$. L: Low group, M: Moderate group, H: High group. $\mathrm{Sig}=$ Significant, $\mathrm{Ns}=$ Not significant $(P>0.05), *=(P<0.05), * *=(P<0.01)$.

\section{Blood parameters:}

In general, serum total protein, albumin, and globulin were significantly affected by ADG and $\mathrm{GH}$ levels in the experimental groups (L, M, and $\mathrm{H}$ ) either, in male or female calves (Figure, 3). However, results showed that the $\mathrm{H}$ group that elevated in ADG and $\mathrm{GH}$ levels had the highest values of serum protein, albumin, and globulin followed by $\mathrm{M}$ group, while the $\mathrm{L}$ group recorded the lowest values. The differences were highly significant $(P<0.01)$ among groups regarded to protein and albumin values in male or female calves.
Also, the same trend was obtained regarded to globulin values except at 9 months old in female groups, while the differences were not significant except at 18 months old in male groups.

Results in Figure 3 revealed that serum glucose and cholesterol values were followed the same trend of total protein and albumin. The high group that elevated in ADG and GH levels had the highest values of serum glucose and cholesterol followed by $\mathrm{M}$ group, while the $\mathrm{L}$ group recorded the lowest values. 

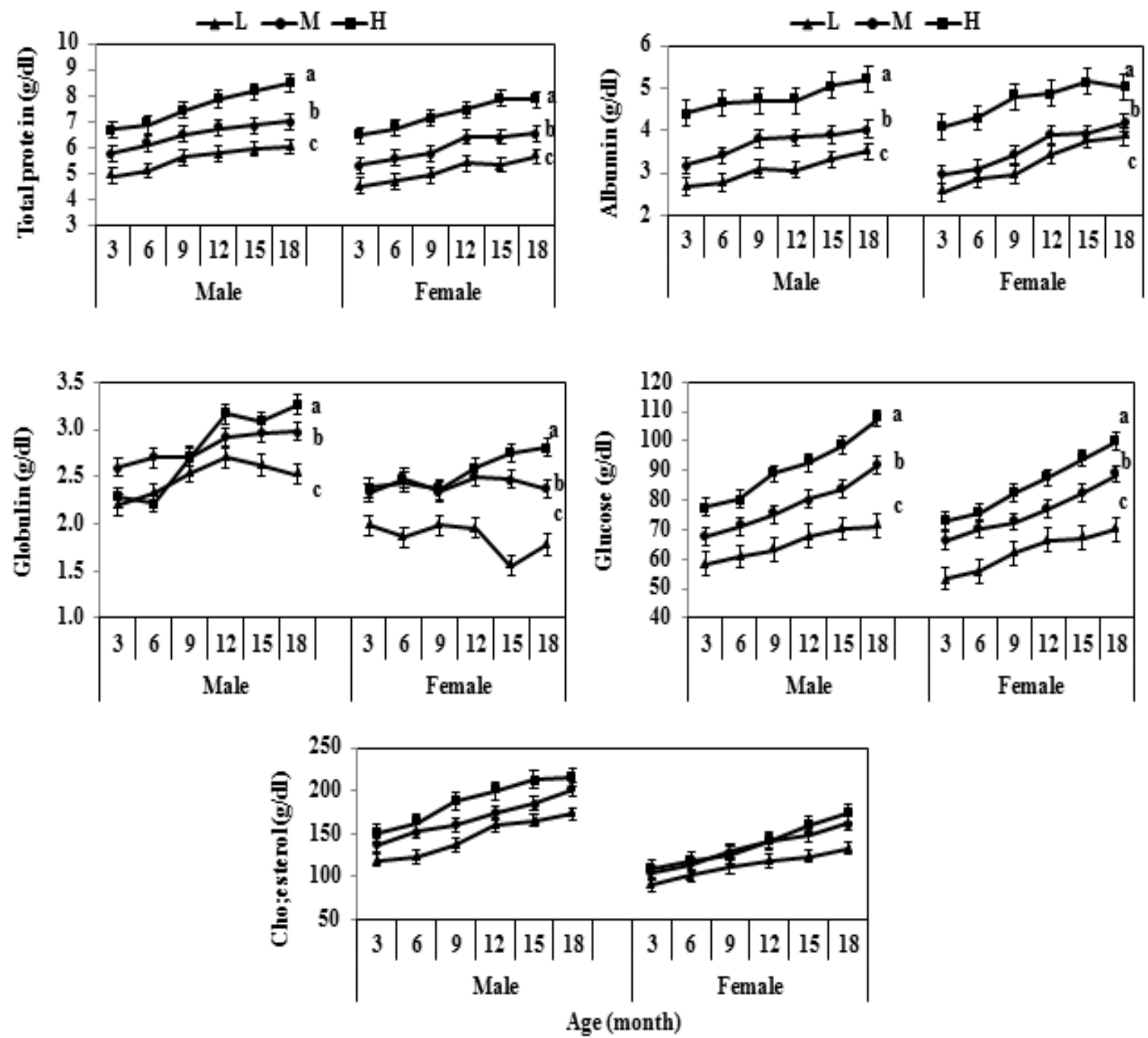

Figure 3: Blood constituents of male and female calves from 3-18 months old $\mathrm{a}, \mathrm{b}$ and $\mathrm{c}$ : Means of different superscripts are significantly different $(P<0.05)$.

L: Low group, M: Moderate group, H: High group.

\section{Reproductive performance of heifers:}

Age at $1^{\text {st }}$ estrous, $1^{\text {st }}$ service, conception and parturition are shown in Table (9). Data showed that heifers had the highest ADG and GH levels ( $\mathrm{H}$ group) recorded significantly $(P<0.01)$ the earliest ages at $1^{\text {st }}$ estrous, $1^{\text {st }}$ service, conception, and parturition followed by heifers had moderate ADG and GH levels (M group), while those had the lowest ADG and GH levels (L group) significantly showed the oldest one. Heifers in the $\mathrm{H}$ group were significantly $(P<0.01)$ increased in weight at $1^{\text {st }}$ service and parturition compared to other groups (M and L). Similarly, by another view, the interval days from the first service to conception, heifers in the $\mathrm{H}$ group seemed the shortest $(P<0.01)$ interval periods overall the rest of growing periods followed by heifers in $\mathrm{M}$ group compared with that in $\mathrm{L}$ group, which had the longest one. It is also worth to note that heifers in the $\mathrm{H}$ group required fewer services to get pregnant (Table 9), relative to other groups. A similar trend was also observed concerning day to reach parturition where heifers in $\mathrm{H}$ group, were significantly $(P<0.01)$ shorter than $\mathrm{M}$ and $\mathrm{L}$. However, there were no significant differences among the experimental groups $(\mathrm{H}, \mathrm{M}$, and $\mathrm{L}$ ) regarding the weight of heifers at $1^{\text {st }}$ estrous and conception. The improvement of the growth and weight of the heifers in $\mathrm{H}$ group at parturition allowed them to give birth without complications, as the number of dystocia cases recorded one case in $\mathrm{M}$ group, 3 cases in L group, while recorded zero in $\mathrm{H}$ group. In addition, birth weight was significantly $(P$ $<0.01)$ increased in $\mathrm{H}$-group $(25.60 \mathrm{~kg})$ relative to 20.60 and $17.25 \mathrm{~kg}$ for $\mathrm{M}$ and $\mathrm{L}$ groups, respectively. Furthermore, the ratio of stillbirth was $(0 \%)$ in $\mathrm{H}$ and $\mathrm{M}$ groups compared to $(20 \%)$ in the $\mathrm{L}$ group. 
Table 9: Reproduction performance of the experimental Baladi heifers.

\begin{tabular}{|c|c|c|c|c|}
\hline \multirow{2}{*}{ Traits } & \multicolumn{3}{|c|}{ Groups } & \multirow{2}{*}{ Sig. } \\
\hline & $\mathrm{L}$ & $\mathrm{M}$ & $\mathrm{H}$ & \\
\hline Age at first estrus (day) & $479.00 \pm 2.89^{\mathrm{a}}$ & $321.80 \pm 12.71^{\mathrm{b}}$ & $286.60 \pm 7.67^{\mathrm{c}}$ & $* *$ \\
\hline Weight at first estrus (kg) & $196.40 \pm 4.04$ & $197.80 \pm 2.87$ & $206.20 \pm 6.81$ & Ns \\
\hline Age at first service (day) & $537.00 \pm 3.97^{\mathrm{a}}$ & $405.80 \pm 12.54^{\mathrm{b}}$ & $360.40 \pm 11.73^{\mathrm{c}}$ & $* *$ \\
\hline Weight at first service $(\mathrm{kg})$ & $218.00 \pm 4.20^{\mathrm{b}}$ & $242.00 \pm 2.77^{\mathrm{b}}$ & $251.40 \pm 5.48^{\mathrm{a}}$ & $* *$ \\
\hline Age at conception (day) & $676.60 \pm 5.47^{\mathrm{a}}$ & $473.80 \pm 11.93^{\mathrm{b}}$ & $411.40 \pm 13.69^{c}$ & $* *$ \\
\hline Weight at conception (kg) & $270.40 \pm 4.85$ & $278.20 \pm 5.10$ & $283.00 \pm 5.56$ & Ns \\
\hline Interval service to conception & $139.60 \pm 3.13^{\mathrm{a}}$ & $68.00 \pm 3.86^{\mathrm{b}}$ & $51.00 \pm 2.38^{\mathrm{c}}$ & ** \\
\hline No. of services / conception & $3.60 \pm 0.20^{\mathrm{a}}$ & $1.80 \pm 0.16^{\mathrm{b}}$ & $1.40 \pm 0.20^{\mathrm{b}}$ & $* *$ \\
\hline Age at parturition (day) & $901.60 \pm 5.47^{\mathrm{a}}$ & $698.80 \pm 11.93^{\mathrm{b}}$ & $636.40 \pm 13.69^{c}$ & $* *$ \\
\hline Weight post-parturition (kg) & $354.20 \pm 6.40^{\mathrm{c}}$ & $388.60 \pm 7.73^{\mathrm{b}}$ & $422.40 \pm 11.90^{\mathrm{a}}$ & $* *$ \\
\hline No. of dystocia cases & $3 / 5(60 \%)$ & $1 / 5(20 \%)$ & $0 / 5(0 \%)$ & \\
\hline Still birth of calves & $1 / 5(20 \%)$ & $0 / 5(0 \%)$ & $0 / 5(0 \%)$ & \\
\hline Birth weight of calves & $17.25 \pm 0.37^{\mathrm{c}}$ & $20.60 \pm 0.66^{b}$ & $25.60 \pm 0.33^{\mathrm{a}}$ & $* *$ \\
\hline
\end{tabular}

a, b and c: Means of each row with different superscripts are significantly different $(P<0.05)$. L: Low group, M: Moderate group, H: High group. $\mathrm{Sig}=$ Significant, $\mathrm{Ns}=$ Not significant $(P>0.05), * *=(P<0.01)$.

\section{DISCUSSION}

Growth hormone $(\mathrm{GH})$ plays a vital role in postnatal growth and general metabolism including for lactation. Thus it is not surprising if $\mathrm{GH}$ has been the most intensive object of studies in ruminant animals to associate mutation of $\mathrm{GH}$ with the productive traits.

There is currently no published literature describing the direct relationship between the growth rate and growth hormone concentration as predicting the performance of subsequent growth and reproductive traits in Egyptian Baladi calves. The present results indicated that the high group was the best group concerning the values of average daily gain (ADG) associated with concentrations of serum GH in both male and female calves compared with moderate and low groups. These results were supported by Oberbauer (2016) who reported that the level of GH had effects either direct or mediated through the induction of IGF-1 to regulate growth rate through its effects on adipose, bone, and muscle. Growth hormone has myriad effects on adipose tissue metabolism (Houseknecht et al., 2000). On the other hand, Torrentera et al. (2009) indicated that the correlations between plasma IGF-1 and ADG or body weight were consistently positive $(0.47$ and 0.48). Krasnopiorova et al. (2012) indicated that GH has wide physiological activities, which include the regulation of growth, gluconeogenesis, lipolysis, and the enhancement of amino acid incorporation into muscle protein.

The data showed that serum GH concentrations regardless of sex declined with advancing age throughout the different groups of study. This decreasing of $\mathrm{GH}$ with increasing age may be due to many causes according to Chapman et al. (1997) who concluded that GH secretion declines with increasing age due to many mechanisms, alone or in combination, include reduced GHRH secretion or action, reduced somatotroph numbers or function and increased sensitivity to the negative feedback effects of IGF-1. A reduction with aging in the level of $\mathrm{GH}$ in the pituitary per unit of body weight has also been observed in cattle (Trenkle, 1970b). The present results are in agreement with Nazaimoon et al. (1993) who indicated that in both sexes showed age-dependent changes in fasting $\mathrm{GH}$ levels $(P<$ 0.001 ) the levels decreased in older human of male and female.

The obtained results showed that the levels of GH from 6-18 months old (Table 3) were gradual decreased compared with the same group at 3 months old (Table 2). These results are compatible with those obtained by Trenkle (1970a) who reported that animals less than 3 months old had higher levels of the $\mathrm{GH}$ than older cattle.

Males consistently had higher levels of GH than females when comparing to the same group (Tables $2 \& 3$ ). These results are in harmony with Trenkle (1970b) who indicated that plasma GH levels were higher $(P<0.05)$ in the bulls as compared with the heifers. Also, Suwitil et al. (2017) found that male cattle have an average GH level higher than from female cattle. However, Nazaimoon et al. (1993) found that there were sex differences in GH levels to be only significant in the pre-pubertal children, being higher in girls than in boys $(P<0.05)$.

Data obtained declared that the $\mathrm{H}$ group within the same-sex achieved the highest level of GH followed by the $\mathrm{M}$ group, while the $\mathrm{L}$ group recorded the 
lowest values. The superiority of the $\mathrm{H}$ group either in male or female calves in $\mathrm{GH}$ levels in different ages from 6-18 months makes them also excel in body weight and ADG as shown in Figure 1 and Table 4. These results may explain the positive relationship between the $\mathrm{GH}$ level and body weight or ADG. The mean volume of GH distribution in serum cattle in the present study ranged from 4.72 to $5.44 \%$ in males and 4.72 to $5.24 \%$ in females of body weight, which similar to volumes of 3.6 to $4.1 \%$ of body weight in cattle as reported by Reynolds (1953). Similar results were obtained by Trenkle (1970c) who indicated that the volume of distribution of GH in plasma cattle ranged from 2.6 to $5.6 \%$ of body weight. Many effects of $\mathrm{GH}$ secretion on body weight development and ADG as found by Oberbauer (2016) who reported that elevated GH postnatal has significant effects on bone, muscle, and adipose tissues. Additionally, GH exerts stimulatory effects on linear growth rates with transient elevation of $\mathrm{GH}$ increasing bone growth rate. At the cellular level, $\mathrm{GH}$ accelerates bone growth. Furthermore, Marett et al. (2014) referred to many known effects of growth hormone to promote lipid mobilization, hepatic glucose production. Aytac et al. (2015) informed that GH directly or indirectly plays an important role in tissue growth and fat metabolism. However, Curi, et al. (2006) reported that the GH gene polymorphism closely associated with growth and slaughter weight in crossbred cattle.

A positive relation was found between body weight and body dimensions. This relation was confirmed by Gilbert et al. (1993) who reported that there was a close correlation between body weight and body dimensions. Also, Van Marle-Köster et al. (2000) described body measurements as selection criteria for growth in cattle. Most of the main body measurements used to predict the weight of cattle are similar to the body measurements used in this study: heart girth, wither height, hip width, body length and hip height using equations proposed by Heinrichs et al. (1992) and Reis et al. (2008).

The differences $(P<0.01)$ in DM, TDN, and CP among experimental groups $(\mathrm{L}, \mathrm{M}$, and $\mathrm{H})$ were affected by both $\mathrm{ADG}$ and $\mathrm{GH}$ levels. Results indicated that the $\mathrm{H}$ group within the same-sex achieved remarkable superiority in the DM, TDN and $\mathrm{CP}$ intake followed by $\mathrm{M}$ group, while $\mathrm{L}$ group recorded the lowest values, and the superiority of $\mathrm{H}$ group may be due to the higher content of $\mathrm{GH}$ associated with high ADG. Also, for the same reason, male groups increased in their consumption than females. Silverstein et al. (1999) suggested that GH stimulates feed intake indirectly through metabolic changes such as increased utilization of nutrients that feedback on hypothalamic centers regulating energy balance. Also, Matty, (1986) reported that $\mathrm{GH}$ enhances growth by stimulating appetite and improving feed and protein conversion. In addition, Silverstein et al. (2000) indicated that the mechanism of rbGH action in promoting growth may include stimulation of appetite and an increase in the level of IGF-I.

The present results showed that feed conversion values of DM, TDN and $\mathrm{CP} / \mathrm{kg}$ gain were reduced by increasing $\mathrm{GH}$ and $\mathrm{ADG}$ levels in $\mathrm{H}$ group compared to other groups ( $\mathrm{M}$ and $\mathrm{L}$ ). Such results are expected, as it was reported that the level of $\mathrm{GH}$ and ADG increased in the male and female calves, feed conversion values decreased (i.e. gain to the best). Al-Husseini et al. (2014) referred that GH was used to improve growth, feed efficiency and to increase returns from grain feeding. The growth hormone improved feed conversion ratio and growth rates of cattle by modifying protein turnover rates in the body (Café et al., 2010).

Serum protein profile, glucose, and cholesterol levels were significant $(P<0.01)$ increased in $\mathrm{H}$ group that elevated in ADG and GH levels either, in male or female calves. This superiority in $\mathrm{H}$ group may be related to high $\mathrm{GH}$ levels affect serum total protein compared to $\mathrm{L}$ and $\mathrm{M}$ groups. The growth hormone level plays an important role in some physiological processes, contributes to improving feed conversion rate, and also increases protein synthesis (Gao et al., 2006). Also, increased total protein in $\mathrm{H}$ group may be due to the higher $\mathrm{CP}$ intake (Tables $5 \& 6$ ) and increasing metabolic rate due to elevated thyroid hormones. Collier et al. (1984) reported that the pituitary thyroid axis is an important physiological factor controlling metabolic processes. In addition, $\mathrm{H}$ group had the highest level of GH, which supports secretion of thyroid hormones as indicated by Lapierre et al. (1990) who reported that thyroid hormones synergize with GH to promote growth. This result may be attributed to the increases in voluntary feed intake as DM and TDN (Tables 5 \& 6). In addition, GH plays an important role in regulating whole-body energy utilization and well-lipolytic action (Lee et al., 2006). Furthermore, Brian et al. (2004) showed that GH had the mechanism to act on an increase in growth rate, feed consumption, and whole-body fat deposition. Moreover, Renaville et al. (2002) reported that GH synthesized in the pituitary gland and acts directly on liver and adipose tissue to regulate gluconeogenesis, proteosynthesis, lipogenesis, lipolysis, and insulin secretion by binding to growth hormone receptor (GHR). Meanwhile, the existence of the axis between GH and IGF-1 has played a vital role in the regulation of metabolism and GHR combines with GH to stimulate a series of metabolic activities by producing IGF-1 in the target tissues, especially in liver (Yang et al., 2019).

Improvement of the reproductive performance of calves may be due to elevating ADG and GH levels 
of $\mathrm{H}$ group, which fed on the higher levels of DM, TDN and CP (Tables $5 \& 6$ ) and improved feed conversion (Tables $7 \& 8$ ) to be more efficient utilize for growth. Renaville et al. (2002) reported that GH synthesized in the pituitary gland and acts directly on the liver and adipose tissue to regulate gluconeogenesis and IGF-1 secretion. Results obtained were in harmony with those recorded by El-Banna et al. (2004) who indicated that level of nutrition has no significant effect on some reproductive traits of Baladi heifers and in the meantime has a significant effect on some other reproductive ones. On the other hand, El-Ashry et al. (2008) concluded that animals fed on the low level were significantly oldest at puberty, $1^{\text {st }}$ estrous and conception than those fed high levels. Increasing energy and protein intake were reported to have a positive correlation with body condition and reproduction of bovine (Peters and Ball, 1995). Increasing glucose level (Figure 3) may improve the reproductive efficiency through coordinating the biological activity of gonadotropin hormones (Hafez, 1993). Glucose is known to have a direct effect on the hypothalamus, which causes the release of GnRH, which in turn causes LH release from the pituitary (Wade and Jones, 2004). In addition, glucose elicits increases in circulating insulin and insulin-like growth factor 1 (IGF-1), which has positive effects on follicular growth (John and Shields, 2013). Also, Peters and Ball (1995) found that increase blood serum glucose cause an increase in serum IGF-1. This may be a possible hormonal mechanism by which nutritional effects might be recognized centrally. Furthermore, IGF-1 has an effect on the rate of increase in the bioactivity of $\mathrm{LH}$ and to augment FSH-stimulated induction of $\mathrm{LH}$ receptors and subsequent progesterone synthesis.

\section{CONCLUSION}

This study supports the hypothesis that blood serum $\mathrm{GH}$ plays a role in growth performance and fertility in Egyptian male or female calves. Therefore, data of ADG associated with GH concentration may be a useful aid in selecting strategies for improving growth efficiency and reproductive performance.

\section{REFERENCES}

Al-Husseini, W.; Gondro, C.; Quinn, K.; Café, L.M.; Herd, R.M.; Gibson, J.P.; Greenwood, P.L.; and Chen, $Y$. (2014): Hormonal growth implants affect feed efficiency and expression of residual feed intake-associated genes in beef cattle. Animal Production Science, 54, 550-556.

Aytac, A.K.; Bilal, A.K. and Davut, B. (2015): Determination of the alui polymorphism effect of bovine growth hormone gene on carcass traits in Zavot cattle with analysis of covariance. Turk. J. Vet. Anim. Sci., 39: 16-22.
Brian, C.P.; Brian, C.S. and Brian, G.B. (2004): Effects of bovine growth hormone (PosilacR) on growth performance, body composition, and IGFBPs in two strains of channel catfish. www.elsevier.com/locate/aqua-online. 232, 651663.

Café, L.M.; Mclntyre, B.L.; Robinson, D.; Geesink, G.H.; Barendse, W. and Greenwood, P.L. (2010): Production and processing studies on calpainsystem gene markers for tenderness in Brahman cattle: 1. Growth, efficiency, temperament, and carcass characteristics. Journal of Animal Science 88, 3047-3058.

Chapman, I.M.; Hartman, M.L.; Pezzoli, S.S.; Harrell, F.E.; JR.; Hintz, R.L.; Alberti, K.G. M.M. and Thorner, M.O. (1997): Effect of Aging on the Sensitivity of Growth Hormone Secretion to Insulin-Like Growth Factor-I Negative Feedback. Journal of Clinical Endocrinology and Metabolism. Vol. 82, No. 9, 2996-3004.

Collier, R.; McNamara, J.; Wallace, C. and Dehff, M. (1984): A review of endocrine regulation of metabolize during lactation, J. Anim. Sci., 59: 498.

Connor, E.E.; Barao, S.M.; Douglass, L.W.; Zinn, S.A. and Dahl, G.E. (1999): Predicting Bull Growth Performance and Carcass Composition from Growth Hormone Response to Growth HormoneReleasing Hormone. J. Anim. Sci. 1999. 77: 27362741.

Curi, R.A.; Palmieri, D.A.; Suguisawa, L.; De Oliveira, H.N.; Silveira, A.C. and Lopes, C.R. (2006): Growth and carcass traits associated with GH1/Alu I and POU1F1/Hinf I gene polymorphisms in Zebu and crossbred beef cattle. Genet. Mol. Biol. 29(1): 56-61.

Duncan, D.B. (1955): Multiple ranges and multiple F. Test. Biometrics, 11: 1. Editor 22.0 License Authorization Wizard, Chicago, USA.

El-Ashry, M.A.; Shahin, G.F.; Monayer, T.I. and Mehany, S.B. (2008): Effect of feeding different concentrate: corn silage ratio on body weight and age at conception of buffalo heifers. Egyptian J. Nutrition and Feeds. 11 (2): 277.

El-Banna, M.K, Ibrahim, S.A.; Shabrawy, H.M. and Enas R. El-Sedfy (2004): Relationships among plan of nutrition, weight gain, age at puberty and reproductive performance in Baladi Heifers. J. Agric. Sci. Mansoura Univ., 29: 1091.

Gao, X.; Xu, X.R.; Ren, H.Y.; Zhang, Y.H.; Xv, S.Z. (2006): The effects of the GH, IGF-I and IGFIBP3 gene on growth and development traits of nanyang cattle in different growth period. Hereditas 28, 927-932.

Gilbert, R.P.; Bailey, D.R.C. and Shannon, N.H. (1993): Linear body measurements of cattle before and after 20 years of selection for post weaning gain when fed two different diets. J Anim Sci 71, 171220.

Habeeb, A.A.M.; EL-Masry, K.A. and ATTA, M.A.A. (2014): Growth Traits of Purebred and Crossbred Bovine Calves During Winter and Summer Seasons. 4th Int. Con. Rad. Res. Appl. Sci., Taba, Egypt, P. 1-10.

Habeeb, A.A.M.; ATTA, M.A.A.; El-Tarabany, A.A. and Gad, A.E. (2017): Improving Live and Dry Body Weight Gain of Bovine Native Calves during Hot Summer Season of Egypt using Genetic Crossing 
Process. Journal of Animal Husbandry and Dairy Science.Vol. 1, Iss. 1, 28-37.

Hafez, E.S.E. (1993): Reproduction in farm animals. $6^{\text {th }}$ ED. PP. 20-55 (ED). Hafez, E. S. E. and Pibiger, philedlphia, PA. USA.

Heinrichs, A.J.; Rogers, G.W. and Cooper, J.B. (1992): Predicting body weight and wither height in Holstein heifers using body measurements. Journal of Dairy Science, 75(12): 3576-3581.

Houseknecht, K.L.; Portocarrero; C.P.; Ji, S.; Lemenager, R. and Spurlock, M.E. (2000): Growth hormone regulates leptin gene expression in bovine adipose tissue: correlation with adipose IGF-1 expression. Journal of Endocrinology, 164(1): 51-7.

John, P.M. and Shields, S.L. (2013): Reproduction during lactation of dairy cattle: Integrating nutritional aspects of reproductive control in a systems research approach. Animal Frontiers vol. 3(4): 76.

Krasnopiorova, N.; Baltrènaitè, L.; Miceikien, I. and Janušauskas, $K$. (2012): Growth hormone gene polymorphism and its influence on milk traits in cattle bred in lithuania. Vet. Med. Zoot., 58(80): 42-46.

Lapierre, H.; Petitclerc D.; Pelletier G.; Delorme, L.; Dubreuil, P.; Morisset, J.; Gaudreau, P.; Couture, Y. and Brazeau, P. (1990): Effect of growth hormone releasing factor and (or) thyrotropin releasing hormone factor on hormone concentration and milk production in dairy cows. Can. J. Anim. Sci., 70:175.

Lee, H.G.; Hong, Z.S.; Kim, M.K.; Kang, S.K.; Xu, C.X.; Cho, J.S.; Seo, K.S.; Roh, S.G. and Choi, Y.J. (2006): The response of plasma leptin and feed intake to growth hormone administration in Holstein calves with different planes of nutrition. Can. J. Anim. Sci. Downloaded from pubs.aic.ca by TOHOKU UNIVERSITY on 08/20/14

Marett, L.C.; Auldist, M.J.; Wales, W.J.; Macmillan, K.L.; Di Giacomo, K. and Leury, B.J. (2014): Evaluation of growth hormone response to insulininduced hypoglycaemia in dairy cattle during a 670-day lactation. Animal Production Science, 54, $1323-1327$.

Matty, A.J. (1986): Nutrition, hormones and growth. Fish Physiol. Biochem. 2, 141-150.

MOA (2007): Ministry of Agriculture and Land Reclamation, Economic Affairs Sector, Study of Statistics for Animal, Poultry and Fish Wealth for year, 2006, p. 1-22.

Nazaimoon, W.M.W.; Ng, M.L.; Osman, A.; Tan, T.T.; Wu, L.L. and Khalid, B.A.K. (1993): Effect of Gender and Age on Fasting Serum Growth Hormone Levels in Normal Subiects. Med J Malaysia Vol 48 No 3, 297-302.

NRC (2001): Nutrient Requirements of Dairy cattle $7^{\text {th }}$ ed. Natl. Research Council, Acad. Press, Washington, DC. USA.

Oberbauer, A.M. (2016): Developmental programming: The role of growth hormone. J. Anim. Sci. Biotechnol., 6(8): 1-7.

Oguro, M.; Ishikawa, H.; Ohtsuka, H.; Hoshi, F. and Kawamura, S. (2003): Clinical evaluation of growth hormone secretion in cattle using insulin tolerance test. The Journal of Veterinary Medical Science 65, 809-812. doi: 10.12 92/jvms.65.809.
Peters, A.R. and Ball, P.J.H. (1995): The postpartum period. Reproduction in cattle $2^{\text {nd }}(\mathrm{Ed})$ PP. 145.

Reis, G.L.; Albuquerque; F.H.M.A.R.; Valente, B.D.; Martins, G.A.; Teodoro, R.L.; Ferreira, M.B.D. and Madalena, F.E. (2008): Predição do peso vivo a partir de medidas corporais em animais mestiços Holandês/Gir. Ciência Rural, 38(3), 778-783.

Renaville, R.; Hammadi, M. and Portetelle, D. (2002): Role of the somatotropic axis in the mammalian metabolism. Domest. Anim. Endocrinol., 23, 351360.

Reynolds, M. (1953): Plasma and blood volume in the cow using the T-1824 hematocrit method. Amer. J. Physiol. 173: 421.

Silverstein, J.T.; Shearer, K.D.; Dickhoff, W.W. and Plisetskaya, E.M. (1999): Regulation of nutrient intake and energy balance in salmon. Aquaculture 177, 161-169.

Silverstein, J.T.; Wolters, W.R.; Shimizu, M. and Dickhoff, $W . W$. (2000): Bovine growth hormone treatment of channel catfish: strain and temperature effects on growth, plasma IGF-I levels, feed intake and efficiency and body composition. Aquaculture 190, 77-88

SPSS (2013): Statistical package for social sciences, IBM $^{\circledR}$ SPSS Statistics Data

Suwitil, N.K.; Besung, I.N.K. and Mahardika, G.N. (2017): Factors influencing growth hormone levels of Bali cattle in Bali, Nusa Penida, and Sumbawa Islands, Indonesi. veterinaryworld.org/Vol.10/October-2017/14. pdf, 1250-1254).

Torrentera, N.; Cerda, R.; Cervantes, M.; Garces, P. and Sauer, W. (2009): Relationship between blood plasma IGF-1 and GH concentrations and growth of Holstein steers. Asociación Latinoamericana de Producción Animal. Vol. 17, Núm. 1, 2: 37-41.

Trenkle, A. (1970a): Growth hormone secretion in cattle and sheep. Journal Paper No. 5-6595 of the Iowa Agriculture and Home Economics Experiment Station, Ames, 242-256. https:// meatscience.org/growth-hormone-secretion-incattle and-sh

Trenkle, A. (1970b): Solid -phase radioimmunoassay for sheep growth hormone. Proc. Soc. Exp. Biol. Med. 133: 1018.

Trenkle, A. (1970c): Growth hormone secretion rates in cattle. Journal of Animal Science vol. 32, no. I, 115- 118.

Van Marle-Köster, E.; Mostert, B.E. and Van derWesthuizen, J. (2000): Body measurements as selection criteria for growth in South African Hereford cattle. Arch Tierz 43, 5-15.

Wade, G.N. and Jones, J.E. (2004): Neuroendocrinology of nutritional infertility. Am. J. Physiol. Regul. Integr. Comp. Physiol. 287: R1277-R1296.

Yang, C.; Zhang, J.; Ahmad, A.A.; Bao, P.; Guo, X.; Long, R.; Ding, X. and Yan, P. (2019): Dietary Energy Levels Affect Growth Performance through Growth Hormone and Insulin-Like Growth Factor 1 in Yak (Bos grunniens). Animals, 9, 39; doi: 10.3390/ ani9020039.

Zahed, S.M.; El-Gaafarawy, A.M. and Aboul-Ela, M.B. (2001): Reproductive performance of a herd of Egyptian Baladi cattle. J. Agric. Sci. Mansoura Univ., 26: 5361. 


\section{توقع الأداء الإنتاجي والتناسلى للعجول البلاي المصرية كإستجابة لمعدل النمو

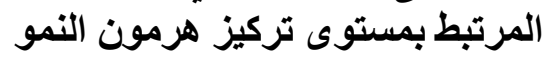

\section{محمود بيسن محله ، أحد محله عبل الحفيظ ، مصطفى قطب البنا ، سمبح محله زاهد}

E-mail: dr_yassin2005@yahoo.com Assiut University web-site: www.aun.edu.eg

أجريت هذه الدراسة لتحديد ما إذا كان معدل النمو المرتبط بتركيز هرمون النمو أداة مُفيده أم لا للتتبؤ بأداء النمو اللاحق والصفات التناسلية في العجول البلدي المصرية. لهذا الغرض ، تم استخدام واحد وثلاثين عجل (7 ا ذكر و 10 أنثى) في هذه الدراسة. تم تقسيم العجول من نفس الجنس (ذكور أو إناث) من الولادة وحتى اليوم التسعين من العمر إلى ثناث مجموعات (منخفضة ، متوسطة و عالية) وفقًا لمتوسط الزيادة اليومية فى وزن الجسم مع تركيز هرمون النمو على النحو التالي: المجموعة المنخفضة ، و التي سجلت

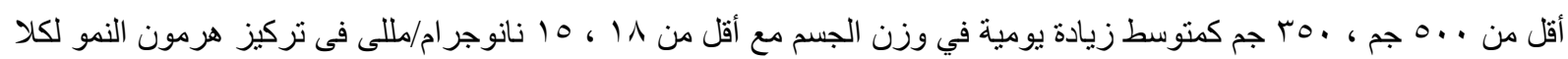

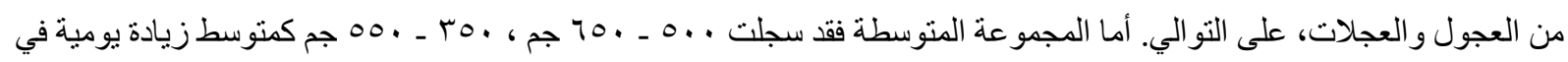

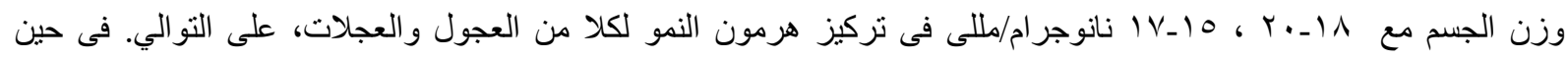

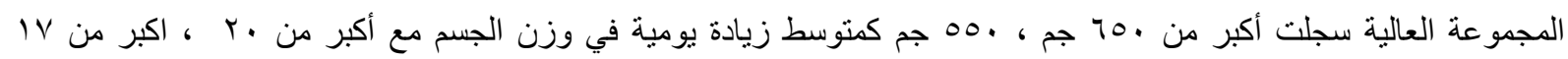
نانوجر ام/مللى فى تركيز هرمون النمو لكلا من العجول والعجلات، على التو الي.

أظهرت النتائج: أن المجموعة العالية حققت أعلى قيم فى متوسط الزيادة اليومية في وزن الجسم وكذلك أعلى تركيز لهرمون النمو في مصل الدم ، تليها المجموعة المتوسطة ، في حين سجلت المجموعة المنخفضة أدنى القيم. أيضا ، أخذت قياسات الجسم (سم) التي تضمنت طول الجسم ، وعرض الوركين ، وإرتفاع الكتفين ومحيط الصدر نفس اتجاه وزن الجسم ومتوسط الزيادة اليومية في وزن الجسم. تأثرت قيم المأكول من المادة الجافة ، مجموع المركبات الغذائية المهضومة ، و البروتين الخام بين المجاميع المختبرة (المنخفضة ، المتوسطة و العالية) نأثر اً معنوياً (0.01 > P) بمتوسط الزيادة اليومية فى وزن الجسم وكذلك تركيز هرمون النمو. كما ظهرت اختلافات كبيرة فيما يتعلق بمعامل تحويل المادة الجافة ، مجموع المركبات الغذائية المهضومة ، و البروتين الخام في بعض فئل أنشهر العمر سواء فى العجول أو العجلات. كان لاى المجموعة العالية والمرتفعة فى متوسط الزيادة اليومية في وزن الجسم وكذللك تركيز هرمون النمو أعلى قيم للبروتين الكلى والألبيومين والجلوبيولين فى مصل الدم تلتها المجموعة المتوسطة ، بينما سجلت المجموعة المنخفضة أدنى القيم. أخذت قيم الجلوكوز والكوليسترول نفس اتجاه البروتين الكلي. ظهرت العجلات التى كانت في المجموعة العالية متفوقة في معظم الصفات التتاسلية مقارنة بالمجموعتين المنخفضة و المتوسطة. يمكن أن نخلص إلى أن إستخدام بيانات منوسط الزيادة في وزن الجسم منز امناً مع تركيز هرمون النمو قد تكون أداة مفيدة في إستر اتيجيات الإنتخاب لتحسين كفاءة النمو و الأداء التناسلى. 